\title{
The second assistant in cardiac surgery: The challenges and answers
}

\author{
T. K. Susheel Kumar, MD
}

We can't all be captains, some have got to be crew, There is something for all of us here.

There is big work to do and there is lesser to do,

And the task we must do is in there.

\section{—Douglas Malloch}

All cardiac surgeons begin their careers as second assistants in the operating room. Superfluous as this statement may appear, there is little mention in the surgical literature of the challenges of being a second assistant. This subject may appear trivial to those no longer in the role, but it is worth remembering that this is not only the earliest stage in a surgeon's career, but also the most impressionable. Surprisingly little has been written about the demands of this role. Much has been written about the qualities a surgeon should possess, but little mention is made of the specific challenges faced in the earliest part of his or her career. In his book De re medicina, one of the first books to be published in the history of medicine, Aurelius Cornelius Celsus, a great authority on the subject, vividly described the qualities a surgeon should possess. He mentioned that a surgeon should have strong and steady hands, a sharp vision, and an undaunted spirit. ${ }^{1}$ Thomas Vicary, ${ }^{2}$ a sixteenth century surgeon, described what he considered the four most important qualities of a surgeon: the surgeon should be learned, expert, ingenious, and well mannered. Much later, William Halsted, ${ }^{3}$ pioneer of modern surgical training, stressed the need for a proper system to produce competent surgeons. His work has been followed by tons of material by different authors, all devoted to the description of the surgeon. However, all these authors allude primarily to the role of the primary surgeon, although there are occasional references to the first assistant. One cannot avoid the feeling that the second assistant has been ignored all along. The Royal Australasian College of Surgeons ${ }^{4}$ recently published a guide book called Surgical Competence and Performance, which provides a framework for assessing surgeons. Some of the markers in this guide have been borrowed from the NOTSS (Non Technical Skills for Surgeons) program of the Royal College of Surgeons, Edinburgh. Although the guide stresses the importance of teamwork in the operating room, the specific issues of second assistants have not been

\footnotetext{
From the Division of Cardiovascular Surgery, Children's National Medical Center, Washington, DC

Received for publication Jan 3, 2009; accepted for publication March 7, 2009.

Address for reprints: T. K. Susheel Kumar, MD, Department of Cardiovascular Surgery, Children's National Medical Center, 111, Michigan Ave, NW, Washington DC 20010 (E-mail: tksusheelkumar@hotmail.com).

J Thorac Cardiovasc Surg 2009;137:1311-4

0022-5223/\$36.00

Copyright (c) 2009 by The American Association for Thoracic Surgery

doi:10.1016/j.jtcvs.2009.03.008
}

addressed. In short, the training of the second assistant has always been done in an informal and tacit manner without being explicitly addressed.

It is also not unusual for a surgeon to face this stage much later in his or her career after developing the skills of a first assistant or the main surgeon. This is a very common situation for surgeons who come into a new setup as either fellows or junior consultants. Many centers make it mandatory for new physicians joining a team to spend a certain amount of time as second assistants. Although this is perfectly understandable, the problem arises when trainees in fellowships or training posts get stuck in that role. This means that whatever has to be learned has to be done in the role of a second assistant. Such stories of surgeons who travel abroad to seek training are very common. The only option in these circumstances is to make the best use of the position of second assistant. This is especially relevant to foreign surgeons in their first year of fellowship training in the West.

\section{THE CHALLENGES}

The challenges of being a second assistant are indeed unique. First of all, it is a job that unlike that of the first assistant does not require step-by-step involvement with the primary operating surgeon. Many steps of an operation can be assisted entirely by the first assistant with the second assistant just watching these steps. It is not unusual in such situations for the second assistant to feel passive and left out of the core operating team. Herein lies the greatest challenge: to stay involved without being physically active. There must be hardly any surgeon who did not find this role somnolent at times (Figure 1).

The second obstacle that a second assistant faces is more technical. Even if he or she is paying attention to everything that is happening, there are many times when the anatomy or lesion being treated cannot be seen clearly. All that one can do in such circumstances is to visualize an image of what is being described by the operating surgeon. Again, it is very easy to get discouraged and lose focus on the operation. Although modern theaters have headlight cameras that allow everyone in the operating room to follow the procedure, the images often are not very clear and not all centers are equipped with such facilities.

The last hurdle that is faced is more a mental challenge than technical. Everybody recognizes the fact that the job of a second assistant involves lesser skills than either the primary surgeon or the first assistant. Thus, it is not uncommon for some hospital documents to name the main surgeon and the first assistant without mention of the second assistant's contribution. As minor an issue as this may seem, it can be very defeating and add to the overall feeling of not being a part of the core operating team. 


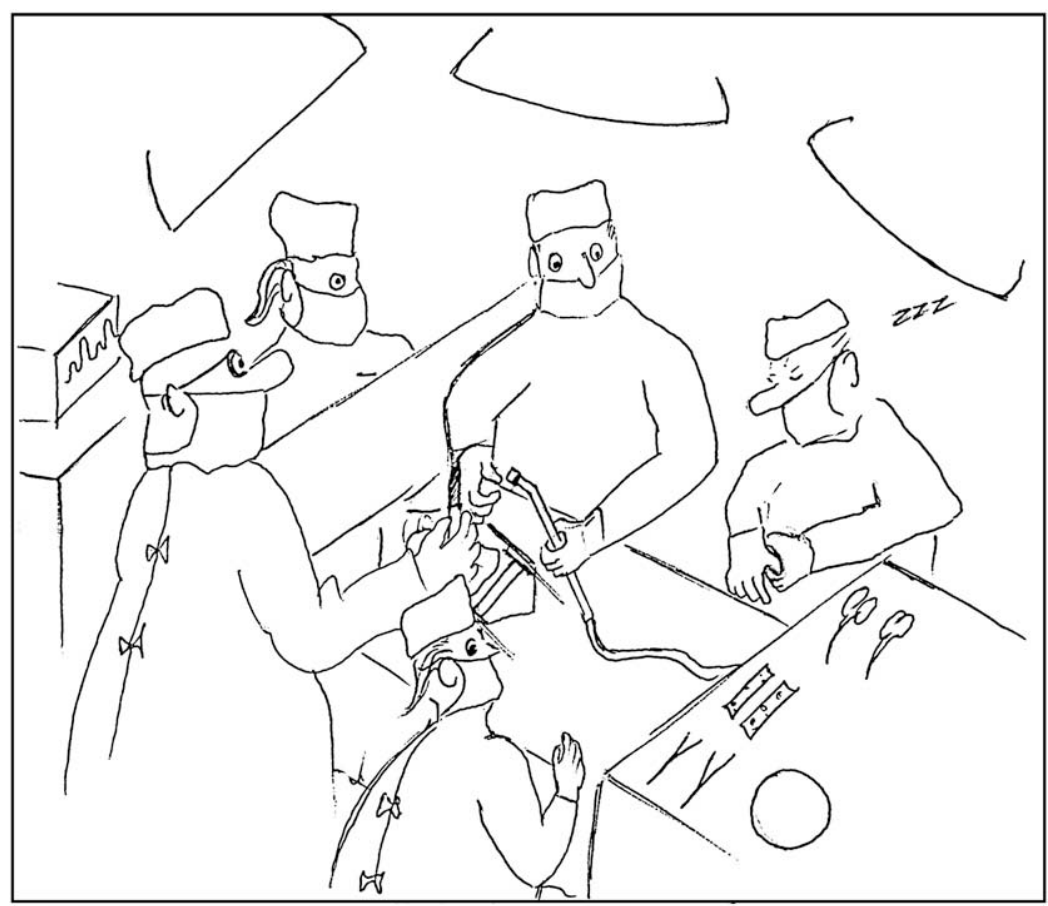

"Hey Susan, your drugs seem to act on my second assistant all the time too."

FIGURE 1. A cardiac surgical team at work.

\section{TACKLING THE CHALLENGES}

Greatness is not in where we stand, but in what direction we are moving.

\section{-Oliver Wendell Holmes}

The best way to really get involved in the operation starts with some homework beforehand. Reading the relevant material and anticipating the steps greatly helps in keeping one glued to the surgical procedure. Talking with the family and building a rapport with the patient are great ways to increase one's commitment to the patient and hence the operation. One should continuously make mental notes of the way the surgeon is carrying out the steps. The trick is to get in the head and mindset of the primary surgeon. Continuous self-questioning to realize the rationale of the various steps is the best form of self-training. Experienced surgeons can make even some of the most technically difficult steps look deceptively simple, and although it may not seem worth making mental notes at the time, in the future, as the trainee stands on the right side of the table, the notes will pay off. The trainee who realizes this early in his or her career will understand the importance of continuous and close observation of the surgeon's movements. All great surgeons will attest to this fact. If opportunity arises, the trainee of first assistants should never shy from asking questions and clarifying the approach.
The second assistant's job does not, however, end with the operation. After the operation, the second assistant should meticulously record all the surgical steps in the form of written notes. There is no better way to record information than the age-old method of handwritten notes with simple diagrams and sketches. This can be very demanding in terms of both time and searching one's memory, but there is no alternative. It is worth reminding oneself that understanding the principles is as important as the hands-on experience. As one's record files get thicker, one's confidence will grow. There is a joy in being able to guess the steps of the surgeon in subsequent operations, and this skill brings with it a level of confidence. One can slowly realize the progress being made, and this builds into a self-perpetuating improvement cycle with each passing day. That is not to say that this is a substitution for actually performing an operation. There is definitely no better thing than to be taken through an operation step by step by an experienced surgeon standing opposite the trainee. But not many trainees are so lucky, and even they realize how few and far between the chances are. In such circumstances, recording is the next best alternative. In a way, recording and rerecording and then meticulously executing the same will decrease the chances of things going wrong when one begins to operate independently. Many surgeons did their first major operation 
independently and did so by repeated observation and recording of the details. No one was ever so gifted as to operate from memory, although it may be may be made to look that way! It is a myth that the biggest names in cardiac surgery got the best operating chances in their training period. What may actually be closer to the truth is that these were the men and women who understood the importance of keen observation, systematic recording of information, and meticulous execution of the same when they had their oppurtunities. Half an hour of observation in Dr Richard Lower's animal laboratory is all that Christiaan Barnard needed to understand the essence of heart transplantation! $!^{5}$

Anyone who second assisted will recount how difficult it is to be able to see the actual field of work in certain stages of surgery. In such circumstances, it is easy to lose track of the operation and feel lost. Paying close attention to the commentary of the surgeon or the first assistant helps in quality imagination and keeping track of the surgical operation. A discussion of the missed pieces of imagery after the removal of the aortic crossclamp during rewarming is an intelligent way of catching up with what was missed and completing the jigsaw puzzle. As mentioned earlier, some theaters are equipped with a headlight camera that may enable the second assistant to watch what cannot be seen on the operating table. This is still a poor substitute for actual view of the field and not all centers can provide such facilities.

The third obstacle, as mentioned before, is more a mental barrier and is easier to tackle if one remembers to do the best job in the role offered. One should remember that a chain is as strong as its weakest link. Thus, proper execution of the operation depends as much on the second assistant as anyone else in the operating team. Who gets credit is the last thing that should concern a surgeon.

\section{THE ADVANTAGES}

Remember the age-old saying that every dark cloud has a silver lining. The role of the second assistant is no different. The position definitely offers certain advantages.

In terms of step-by-step assistance, the second assistant's role is not as intense as that of a first assistant; thus, there are opportunities to stop and think about what is happening. In other words, a second assistant has more time than a first assistant to rationalize and make a mental flow chart. On the other hand, a first assistant has to match the pace of the main surgeon at every stage and does not have the luxury of mental breaks in the action. At the same time, it is easy for the second assistant to get lost in thoughts and make it seem like he is "sleeping" at the table. Hence, this advantage must be used with caution. At certain times the field offers a great view to the second assistant, and that opportunity should be used well to get a good insight into the anatomy.

\section{THE SURGEON'S ROLE}

Surgery is truly all about teamwork. Understanding of the aforementioned challenges to the second assistant by the main surgeon can make a huge difference. Planning the surgical steps to keep the second assistant more physically active is a great way of keeping him or her involved. For example, putting the second assistant in charge of clamping and declamping the venous lines will keep him or her alert and provide a sense of responsibility. Even if a step could be managed entirely by the first assistant, delegating a part of the step to the second assistant is a wise way of maintaining interest.

A running commentary by the operating surgeon is tremendously helpful for the assistants. Explaining what is being done and why is a hallmark of a great teacher. Addressing the assistants by their names while commenting gives a sense of importance to them. Asking questions and soliciting opinions is a superb way of keeping the assistants involved. The surgeon should not forget that some of the best ideas can come from the most junior members of the team. This will automatically get them to put in their best efforts.

Appreciation is a powerful tool that an operating surgeon should possess. A small word of appreciation to the assistants does much good, whereas severe criticism will usually only have a negative result and make the job even more difficult for the assistants. A wise surgeon should remember that no assistant would deliberately harm the patient. If they are taught properly, there is no reason why assistants should not improve with every case. After all, cardiac surgery is not the toughest job in the world!

I hope that this editorial will prove useful to all those young trainees and fellows who are presently in the role of the second assistant while reminding the senior surgeons of the demands of the second assistant, a stage they once passed through, and the ways in which the role could be made more productive and enjoyable.

\section{References}

1. Brieger GH. The development of surgery. In: Sabiston DC, ed. Textbook of surgery. 14th ed. Philadelphia: WB Saunders; 1991. p. 1-18.

2. Vicary T. The Englishman's treasure. With the true anatomie of man's body London. 1633.

3. Halsted WS. The training of the surgeon. Bull John Hopkins Hosp. 1904;15:267.

4. Surgical competence and performance. 1st ed. Melbourne: Royal Australian College of Surgeons; 2008. p. 2-29.

5. Stoney WS. Pioneers of cardiac surgery. 1st ed. Nashville: Vanderbilt University Press; 2008. p. 440-6.

\section{Invited Commentary}

The article by Dr Kumar on the virtues of being a second assistant and its forgotten benefits is one that struck a helpful and very instructive tone for me. It brought back fond memories of my days as a medical student and junior resident on the surgical services of 
a number of great surgeons and highly respected physicians with whom I had the honor of working.

Likewise, it brought back memories of some real tyrants and difficult men (I had the misfortune of having no women as mentors) who were to be my role models and subconsciously I admired and wanted to emulate.

In the end, my career choices were most fortunate to bring me to San Antonio, where a fairly young Dr Kent Trinkle and Dr Fred Grover exposed me to a substantially different kind of cardiothoracic surgeon.

After considerable reflection about teachers, students, and all those we work for, it is important to note that we have responsibilities to each other. It includes treating each other with dignity and respect in all situations. There will be times that errors in judgment or technique or advanced patient disease causes unplanned pain, disability, or death. The resultant conflict, anxiety, and any anger produced by the situation must remain focused on the problem produced and not directed to the individuals trying to administer patient care.

Equally important in his article, Dr Kumar has identified and emphasized the worth and high position of a second assistant in cardiothoracic surgery. He notes several great habits from which we can all learn. First, be prepared, do your reading, and review the patients' anatomy and symptoms beforehand. Understand why the patient has agreed to lie down for a life-altering procedure with significant risks. Second, keep your mind engaged and thinking about the next steps. Anticipate the flow of the procedure and, as an assistant, remember to expose the anatomy for the surgeon and resist the temptation to poke your head into the field and complicate the procedure for the operative team. Third, Dr Kumar makes a great point of having personal debriefing sessions of what went well and what did not. Make notes for yourself. This is something that Kent Trinkle did and taught me to do as well. I still have a box chock full of $3 \times 5$ cards on my desk of procedures done over the years of the tricks that worked, the tricks that failed, and steps that backfired or worse.

For those of us who are now senior and able to think back to that day of being a second assistant and reflect critically of themselves and their personal growth as done above, realize that many folks are looking up to you and looking for some sign of acknowledgment or encouragement, however small. I remember being called a "zero" as a medical student by a senior cardiac surgeon and feeling great about it because he had just called his junior partner and the fellow "minuses." The ability to make those supporting you feel needed and important is crucial to the survival and health of your team. Calling a junior person by name or paging someone to thank them for their work on the service as an intern or student has at times lasting value and merit. For me, this article is simply a wonderful reflection of the great times that are to be had in surgery at all levels and a call for all of us to continue to grow professionally and personally in an effort to honor those we serve.

John Calhoon, $M D$

University of Texas Health Sciences Center

San Antonio, Tex 